\title{
HERMENÉUTICA, AUTONOMÍA Y EXPERIENCIA EN LA ESTÉTICA ALEMANA CONTEMPORÁNEA. A PROPÓSITO DE EL ARTE COMO PRAXIS HUMANA. UNA ESTÉTICA DE GEORG BERTRAM
}

Bertram, G. (2016). El arte como praxis humana. Una estética. España: Comares. 2016. Pp. 187.

\section{Por: Naím Garnica ${ }^{1}$}

A dos años de su publicación original (Kunst als menschliche Praxis. Eine Asthetik, 2014) ingresa por primera vez, en manos de la excelente traducción de José Francisco Zuñiga García, un libro completo de Georg Bertram. Este profesor alemán de filosofía de la Freien Universitat Berlin cuenta con una productividad destacada como sorprendente, pues atraviesa diversos campos y tradiciones de discusión filosófica con cierta comodidad. Bertram puede discutir tanto con la tradición analítica como con los herederos de la tradición crítica de la estética alemana (Albrecht Wellmer, Martin Seel, Christoph Menke) y las fuentes de la hermenéutica contemporánea. Probablemente, este hecho tenga que ver con su trayectoria intelectual y formativa que, como bien indica la edición de esta colección de estética de la editorial española Comares, el autor ha investigado al lado de pensadores provenientes de muy diversas corrientes de pensamiento, desde Martin Seel u Odo Marquard hasta los circuitos académicos de Pittsburgh orientados por John McDowell. Esto último es evidente en la reconstrucción de Kant y Hegel que Bertram realiza en los capítulos dos y tres de este texto. Los trabajos de los llamados "neohegelianos de Pittsburgh" o Pittsburgh School (John McDowell, Robert Brandom, Robert Pippin, Terry Pinkard) se vuelven visibles en el análisis de los idealistas alemanes.

${ }^{1}$ CONICET. Universidad Nacional de Catamarca, Argentina. Becario doctoral de CONICET, Argentina. Docente de Introducción a la Epistemología en el profesorado de Ciencias de la Educación y Epistemología I en el profesorado de Filosofía de la Universidad Nacional de Catamarca, Argentina. Licenciado en Filosofía. Sus líneas de investigación son las Teorías del sujeto y la modernidad, filosofía moderna, romanticismo y estética. Entre sus publicaciones recientes se encuentran: (2017) "Critical Irony or the Lovers of Ruins: The Aesthete, the Dandy and the Flâneur”. En: Tópicos, Revista de Filosofía, (52), 151-172. y (2017). "Lenguaje, ideología y política. La ideología estética de Paul de Man”. Nuevo Pensamiento.VII(9), 45-68. E-mail: naim_garnica@hotmail.com

Recibido: 1 de febrero de 2018. Aprobado: 5 de julio de 2018. 
En El arte como praxis humana Bertram desarrolla cuatro capítulos intentando mostrar la posibilidad de reactualizar la consideración sobre el arte, entendiéndolo como una reflexión específica sobre otras prácticas humanas. La intención general de Bertram muestra que, por un lado, el arte es un acontecimiento práctico y, por otro lado, la praxis artística considerada en "el ámbito de la vida humana", pone en cuestión otras prácticas vitales. Por ello, Bertram insistirá en la capacidad del arte como una praxis reflexiva plural que hable de las artes y no del arte. Esto le permitirá al autor desplegar su crítica al concepto de autonomía de la tradición estética alemana desde Kant y Hegel hasta Christoph Menke, como también de Arthur Danto. De cierta forma, el logro del texto se centra en reactivar el sentido del arte dentro de la praxis humana y se abandone, luego de siglos, la concepción que hace descansar la validez del arte en su autonomía. La separación del arte de la vida humana tiene una larga tradición que podría reconocerse desde el romanticismo hasta Adorno gracias al concepto de apariencia estética, algo que Bertram solo parece reconocer tangencialmente. No obstante, el libro desarrolla en sus críticas a la autonomía artística una concepción de arte, en todas sus formas, que no puede escindirse de la vida ni siquiera en su dimensión apariencial.

Precisamente, el primer capítulo, en el cual Bertram lleva a cabo su crítica al concepto de autonomía artística, cifra gran parte del desarrollo posterior del texto. La crítica al paradigma de la autonomía del arte identifica el riesgo que constituye una concepción del arte de tal naturaleza, pues unilateralmente colocó un excesivo énfasis en la especificidad del arte. La pretensión del paradigma de la autonomía de definir el arte como una práctica que difiere de las demás prácticas, cree Bertram, puede conducir a su aislamiento como también su inhabilitación crítica en relación a otras prácticas. Según su planteamiento, esto ha llevado a destacar la diferencia del arte gracias a la consideración del concepto de autonomía como un rasgo esencial del arte. En función de esta caracterización, Bertram denomina paradigma de la autonomía a todas aquellas posiciones que comparten pensar el "arte recurriendo a su especificidad y a su delimitación frente a otras actividades" $\left(2016^{a}\right.$, p. 12). Pese a ello, reconoce que la idea de autonomía podría tener algún potencial si se evita el excesivo énfasis en la unilateralidad de la especificidad del arte. Al respecto, indica que se debe objetar "una comprensión unilateral del concepto de autonomía, para poder poner de manifiesto su núcleo correcto" $\left(2016^{\mathrm{a}}\right.$, p. 12). Bertram se opone a que la autonomía y la heteronomía puedan pensarse como dos elementos separados. Por el contrario, toda autonomía artística "está constitutivamente unida a la heteronomía" $\left(2016^{a}\right.$, p. 12). En esa dirección, las posiciones de 
Christoph Menke y Arthur Danto, como representantes del paradigma de la autonomía, se vuelven problemáticas, dado que adhieren a una descripción del arte a partir de la especificidad del mismo que opera en todo concepto de autonomía.

De ese modo, Bertram encuentra que las posiciones de estos dos autores son representativas de este paradigma de la autonomía artística. En primer lugar, Bertram se opone a la descripción de Menke sobre el arte como un juego de fuerzas desarrollada en su obra $\mathrm{Kraft}^{2}$ (2008), como asimismo, de la explicación de las experiencias estéticas "como experiencias de abandono de la rutina cotidiana" (2016a , p. 15) en el trabajo de 1988 titulado La soberanía del arte ${ }^{3}$. Ambas concepciones son expuestas por Menke en dos textos que distan bastante en el tiempo como en sus desplazamientos conceptuales. Sin embargo, Bertram remarcará que ambas consideraciones sobre el arte no explican la relevancia del arte y, a su vez, dificultan entender el arte como una praxis plural. Esto, encamina al autor a sostener que no se puede explicar la autonomía estética en términos de experiencia estética. Según entiende, "la posición de Menke" no admite "explicar la pluralidad de las artes como rasgo genuino del arte" $\left(2016^{\mathrm{a}}\right.$, p. 22), lo cual implica una reducción del arte a su supuesta especificidad que la aparta del marco de la praxis humana. Tal consecuencia se origina, para Bertram, en la reducción del arte a una experiencia unitaria, esto es, "a una determinada experiencia que hacen los sujetos en el trato con las obras de arte o con acontecimientos estéticos" $\left(2016^{\mathrm{a}}\right.$, p. 23).

A raíz de esto, la propuesta de Menke excluiría mediante la especificidad que le otorga la autonomía artística la pluralidad concreta y el sentido, es decir, todo lo que involucra la praxis del arte. A tales efectos, parece necesario para el lector detenerse con cuidado en los argumentos del capítulo uno. Las críticas al paradigma de la autonomía serán decisivas para la elaboración de la propuesta de Bertram en el capítulo final. Además, el problema de la autonomía es tematizado en el seno de la estética alemana por medio de la reflexión de la categoría de experiencia estética, la cual se convierte en un escollo a superar durante todo el análisis de Bertram. Por tanto, no es casual que el autor considere como una opción de salida del paradigma de la autonomía dejar de preguntarse por las distinciones y particularidades del arte y proponga pensar, antes bien, la relación que existe entre el arte y el resto de la praxis humana. A juicio de Bertram, la dificultad de Menke consiste en que su concepción sólo considera el arte como un bien distintivo que

${ }^{2}$ Menke, Chr. Kraft, Frankfurt: Suhrkamp. 2008

${ }^{3}$ Menke, Chr. Die Souveränität der Kunst: Ästhetische Erfahrung nach Adorno und Derrida, Frankfurt a.M., Athenäum. 1988. (II. ed. ampliada, Frankfurt a.M., Suhrkamp 1991). 
termina por situarse en un contexto metafísico. Menke piensa "la relación del arte con el resto de la praxis humana, en el mejor de los casos, de un modo abstracto" (2016a, p. 36). En consecuencia, esto pondría a Menke, según Bertram, "en la tradición de Benjamin y Adorno, pero conecta al mismo tiempo con el romanticismo y con Nietzsche" (2016a, p. 36).

En relación al otro representante del paradigma de la autonomía, Bertram sostiene que su concepción de la obra de arte supone que a la obra le es constitutiva la interpretación. De esa forma, toda obra de arte es una autointerpretación. Tal autocomprensión muestra un punto de vista estético particular o específico de la obra en la praxis humana en relación a otras formas de praxis. Bertram afirma que una consideración de este tipo sobre el arte contiene los siguientes peligros: a) asignarle un valor en relación a las demás prácticas que termina por diluir el arte como una prácticas más que se autodetermina; b) otorgarle una especificidad radical al arte que no le aporta ningún valor en el marco de la praxis humana. Por ende, Danto sólo se detiene a destacar el momento autónomo y específico del arte sin explicar la relación del arte con la praxis en general. Por tanto, "en Danto retorna un problema que ya conocemos: bajo las auspicios de la autonomía estética, el valor del arte no se deja entender como arte."

En ambos casos, Bertram reconoce la intención de pensar las formas de vida "como trasfondo de la determinación del arte", lo cual conlleva una reducción de las formas de vida humana. Frente a ello, propone entender que la praxis puede presentarse como autodeterminada, pero

precisamente, por estar troquelada a través de momentos de indeterminabilidad que proceden de sí misma [...] es un aspecto de la racionalidad humana. La razón no es, a este respecto, la invariante de la forma de vida humana, sino del proceso de la constante redefinición de los puntos de referencia esenciales dentro de esta forma de vida. Es racional la praxis que, en la determinabilidad, está referida a la indeterminabilidad (2016a, p. 40).

Por tal motivo, Bertram sostiene que Danto y Menke entienden la praxis humana como determinada, olvidando la indeterminación que es constitutiva a toda praxis que se vuelve a pensar y determinar de forma permanente. A causa de esto, el autor indica que "el arte se puede comprender como una praxis en la que son negociadas de nuevo las determinaciones de la praxis humana [...]. El arte es una praxis en la que la determinabilidad está constitutivamente unida a la indeterminabilidad" (2016a, p. 40).

En el segundo capítulo busca encontrar un concepto no reducido de arte a partir del surgimiento histórico-conceptual de la estética. Su descripción, 
siguiendo a Jacques Rancière, de este proceso pone el acento en la génesis kantiana de la estética, apartándose de la reconstrucción baumgarteniana de la estética. A su juicio, Kant, mediante la revolución del conocimiento, ofrece al arte un lugar que lo vuelve comprensible dentro de la praxis humana. Kant se vuelve el "modelo de las posiciones que defienden la autonomía estética; Hegel por el contrario, apadrina a todos los defensores de la determinación filosófica o social del arte" (2016a, p. 45). Justamente, cree Bertram, las reducciones de Menke y Danto bajo el paradigma de la autonomía habrían sido producto de la imposibilidad de captar con claridad estas consideraciones de las estéticas de Kant y Hegel.

$\mathrm{Su}$ estudio sobre Kant se concentra en la concepción de los objetos bellos a partir del placer que generan por la interacción entre las facultades. Esto haría que se presenten posibilidades en torno a la vivificación que el sujeto siente con esa interacción de las facultades. Resume: "en la toma en consideración de objetos bellos los hombres reflejan su capacidad cognoscitiva. Hay que concederle valor a esa reflexión porque proporciona vivacidad los sujetos mediante la experiencia de la interacción entre sus facultades cognoscitivas" (2016a, p. 50). Del planteamiento kantiano, Bertram deduce que no existe una determinación específica de lo bello, en la medida en que el propia Kant identifica lo bello con lo indeterminable y reflexivo. También Hegel permite seguir esta orientación, según la cual lo bello puede pensarse como reflexión. Este último consideraría las capacidades cognoscitivas como histórico-culturalmente a los fines de pensar la reflexión estética en tanto "el arte tematiza las orientaciones esenciales de una forma de vida. Y esta tematización (en este punto concuerda Hegel con Kant) un efecto vivificante" (2016a, p. 54). No obstante, Hegel al analizar la vivificación en virtud ya no de un libre juego de un estado indeterminado, sino "del estado determinado de la confrontación con una obra de arte concreta" (2016a, p. 55), se distancia de Kant en el planteamiento de Bertram.

Pese a tales consideraciones, el autor afirma la existencia de una concepción reducida a la dimensión teórica en la reflexión en Kant y Hegel que impediría llevar a cabo una comprensión del arte como "realización de la libertad". Las prácticas reflexivas deben ser consideradas para el pensador alemán como un elemento necesario de la conformación de la libertad. Por lo tanto, el arte como una praxis de la libertad "debe ser pensada mediante conceptos procedentes de la reflexión práctica, de manera que el arte sea entendido como la praxis específica de la confrontación del hombre consigo mismo" (2016a, p. 73). Bajo estos presupuestos Bertram analiza, en el tercer capítulo, las posibilidades de encontrar un concepto de reflexión práctica del arte. A tales efectos reconstruye las perspectivas de Gadamer, 
Goodman, Hegel, entre otros y muestra de qué modo la obra de arte sería posible pensarla dentro del entramado del mundo. El arte y el mundo se presentan en una relación práctica donde está presente su dinámica, dada las relaciones con actividades interpretativas. Precisamente,

el arte se encuentra más bien en una relación esencial con el resto de las prácticas. Porque existe esa relación, es valioso para nosotros el enfrentarnos a obras de arte [...] las propiedades de las obras de arte con valor estético pertenecen al entramado del mundo en cuanto que suponen un desafío para la toma en consideración del mundo (2016a, p. 118).

Bertram considera que las prácticas estéticas no sólo involucran una recepción pasiva por parte del receptor, sino también que el contacto con la obra conduce a los receptores a nuevas actividades, enfoques y propuestas. La dimensión activa de los receptores, siguiendo a Gadamer, es aquello que permite volver a reconsiderar o re-interpretar la relación con el mundo mediante las prácticas estéticas, además de entender que en ello reside su aporte como praxis humana.

Tal concepción, se vuelve reconocible en el planteo de Bertram, si aceptamos que las actividades receptivas pueden entenderse como "prácticas interpretativas", en tanto esas "actividades están asociadas con la creatividad -con procedimientos experimentales, con nuevos puntos de partida y cosas por el estilo-" (2016a, p. 101). Pero, esto no puede reducirse a una concepción subjetivista en la cual el receptor podría decidir por sí sólo. Antes bien, ahora siguiendo a McDowell, Bertram aclara que las prácticas estéticas deben considerarse en el marco de las formas de vida humana donde se relaciona con otras actividades cotidianas, "cuya renegociación se desencadena cuando se toman en consideración obras de arte" (2016a, p. 122). Mente y mundo $o^{4}$ de McDowell, le permite no olvidar la dimensión objetiva y "corregir" hermenéuticamente la comprensión de la relación interpretativa del receptor con el mundo. Así, explica el autor:

$\mathrm{Al}$ mundo pertenecen también $[\ldots]$ objetos y propiedades que tienen un carácter subjetivo. En relación con las obras de arte de las que se ocupan los receptores, esto quiere decir que las obras de arte confrontan a los receptores con las relaciones que pertenecen a la disposición del mundo $\mathrm{y}$, en este sentido, existen independientemente de ellos. Los receptores

${ }^{4}$ McDowell, J. Mind and World. Cambridge, Mass., London: Harvard University Press. 1994. (McDowell, J. Mente y mundo. Salamanca: Ediciones Sígueme. 2003). 
descubren estas relaciones en el encuentro con las obras de arte -no las inventan- (2016a, p. 109).

En el último capítulo, Bertram desarrolla su propuesta en relación a cómo el arte podría ser considerado como praxis de la libertad. Su tesis indica que sólo es posible tal consideración si el arte, en el sentido de la pluralidad del arte, es explicado como una praxis abierta, indeterminada e insegura. Indica que su propuesta consiste en pensar de qué modo "la obra de arte echa mano de las constelaciones que actualiza. Su fundamento no es el material de un arte particular ni una determinada polaridad en la que están todas las artes" (2016a, p. 132). Dicho supuesto sobre el arte se entiende a la luz de la comprensión de la obra de arte de Bertram como una configuración que se encuentra en un contexto con otras obras. La obra de arte "no se reduce al carácter determinado de un arte individual, sino que está asociado genuinamente al carácter indeterminado del continuo desarrollo de las obras de arte y de las artes" (2016a, p. 136).

El carácter inestable y agonal del arte es posible pensarlo, en el contexto de este texto, si el arte es inseparable del concepto de modernidad. Para el autor, arte y modernidad no pueden concebirse de forma separada. El arte está siempre expuesto al fracaso, porque no hay certeza de si el arte ha logrado tener éxito. El fin del arte, en esa dirección, no es la modernidad como lo ha comprendido la vanguardia. La modernidad no es un fin histórico al que el arte se dirige para su disolución, por el contrario,

el arte es siempre, e intrínsecamente, moderno; y lo es tanto en sus formas tradicionales como en las formas que adopta en la cultura pop. No pone rumbo a la modernidad como si se tratase de un punto histórico en el que amenaza la disolución del arte. Quien afirma tal fin del arte, pasa por alto el carácter inseguro del arte y comprende la modernidad del arte solo en el sentido del vanguardismo (2016a, p.157).

Precisamente, considerar el arte en su carácter inestable le permite a Bertram entender cómo la relación entre la obra y sus receptores forma parte de una interacción dinámica "de un proceso de negociación" (2016a, p. 177), el cual como reflexión práctica desarrolla la praxis humana libre. Esto último, probablemente, explique el subtítulo del texto de Bertram "Una estética", en tanto la praxis no está referida exclusivamente sobre el arte, sino también a la inclusión del arte en una dinámica que involucra otros objetos no artísticos que podrían desafiar al arte mediante su pretensión de convertirse en arte (paisajes o artefactos rituales, entre otras cosas). 
Finalmente, debemos señalar que este texto debería ser complementado con las discusiones al interior de la estética alemana en los últimos 30 años. El impasse de la reflexión en Alemania en relación al arte, luego de los impulsos reflexivos sobre el arte de Heidegger, Gadamer, Jauss, entre otras perspectivas, hasta los años 80, recién logró encontrar en Albrecht Wellmer y sus herederos (Christoph Menke, Martin Seel, Ruth Sonderegger, Juliane Rebentisch $^{5}$ ) la posibilidad de repensar las coordenadas de la dimensión artística en relación a la política y su potencial crítico. Los estudios de estos autores, que conectan la teoría estética de Adorno, la hermenéutica de Gadamer, la reciente filosofía analítica del lenguaje y la filosofía francesa contemporánea, han revitalizado la estética teórica y la filosofía del arte en Alemania. Las obras de esta generación de académicos, cuyos resultados han sido receptados en las humanidades y en el debate al interior de los estudios culturales, posibilitan un estudio más profundo de la reflexión sobre la especificidad de la dimensión estética y sobre las estructuras de la experiencia estética. Cabe señalar que la discusión sobre los conceptos de experiencia y autonomía estéticas ya había sido señalada por Rudiger Bubner. Si tomamos las críticas de Bubner en su ensayo "Sobre algunas condiciones de la estética actual" originalmente publicado en 1973, pero actualizado en 1989, existirían dos razones a principios de los años setenta para mirar de nuevo a la teoría de la experiencia estética de Kant. La primera en relación a la desaparición empírica de las llamadas obras de arte tradicionales y cerradas en favor de acontecimientos estéticos que hicieron depender de su experiencia. La segunda sostiene que tal desaparición no es empírica, sino que es válida para cualquier normativa crítica de la misma, es lo que los filósofos han enaltecido, en especial, la verdad más alta como ubicada en el arte. Las críticas de Bubner están dirigidas, principalmente, en contra de, por un lado, la estética del marxismo y, por otro lado, la estética de la verdad de la hermenéutica de Gadamer. Ambas perspectivas, según Bubner, intentarían resolver los problemas filosóficos en problemas artísticos, reduciendo la verdad del arte en la verdad filosófica. Con la ayuda de los conceptos de "obra" y "verdad" como categorías intempestivas los teóricos de la verdad harían mejor la filosofía del arte. Las estéticas heterónomas, como las califica

${ }^{5}$ Seel, M. (1991): Eine Ästhetik der Natur, Frankfurt a.M., Suhrkamp; Menke, Chr. (1988): Die Souveränität der Kunst: Ästhetische Erfahrung nach Adorno und Derrida, Frankfurt a.M., Athenäum; Sonderegger, R. (2000): Für eine Ästhetik des Spiels. Hermeneutik, Dekonstruktion und der Eigensinn der Kunst, Frankfurt a.M., Suhrkamp; Rebentisch, J. (2003): Ästhetik der Installation. Frankfurt a. M.: Suhrkamp, Rebentisch, J. (2012): Die Kunst der Freiheit. Zur Dialektik demokratischer Existenz. Frankfurt, a. M.: Suhrkamp. Existe traducción al castellano de varias obras de estos autores. 
Bubner, verían una forma de tutelaje del arte mediante el lenguaje filosófico. Si aceptamos esas perspectivas, el arte estaría en la obligación de revelar verdades más profundas, incluso, debería develar verdades filosóficas que la filosofía misma ya no se atreve a hacerlo. Lo que inicialmente parece una revalorización del arte es para Bubner su devaluación, esto quiere decir, reducir el arte a la filosofía. De ese modo, el arte perdería su propia lógica, dado que el peligro con estas estéticas heterónomas sería la subordinación del arte a la filosofía. Esa afinidad entre arte y filosofía permitiría el esclarecimiento mutuo en tanto el horizonte del problema sea compartido.

Sin embargo, Bubner desconfía en que en ese esclarecimiento recíproco se esté cifrando el peligro de dominio de la filosofía sobre el arte. Bubner cree encontrar que el único medio de interpretar el concepto de experiencia estética estaría disponible en el concepto de juicio reflexionante de la estética kantiana ${ }^{6}$. En el análisis de Bubner, el juicio reflexionante debería concebirse, al igual que el concepto de apariencia, como aquello "no autónomo que se ha vuelto autónomo" (2010, p. 399). El tradicional esquema de la teoría del conocimiento sería insuficiente para comprender la apariencia o, dicho kantianamente, - como le gusta a Bubner - la operación. Recurrir a la apariencia como forma de caracterizar el juicio reflexionante y, por tanto, a la experiencia estética le permite a Bubner encontrar una lógica especial del arte que la salve de las pretensiones universalistas de la verdad filosófica. $\mathrm{Si}$ el punto de partida, según Bubner, es la experiencia estética y su estructura el juicio reflexionante, la apariencia estética sería la posibilidad ontológica de la existencia del arte como separado (autonomía) de la filosofía. ${ }^{7}$

Bubner no está de acuerdo con poner al arte y su apariencia autónoma en relación a la verdad exigida por la filosofía. Reconoce que Platón en su intento de desterrar el arte del Estado ideal beneficia y considera seriamente la posibilidad de una autonomización de lo no autónomo. El peligro que

${ }^{6}$ La posibilidad de indeterminación conceptual y búsqueda permanente de la facultad reflexionante ofrecería no sólo una función mediadora, sino también que: "El sujeto se experimenta a sí mismo en sus operaciones, lo que sólo puede suceder si no se da ninguna determinación obligatoria. El objeto que desencadena este proceso permanece indeterminado; por esta razón, la relación con él tiene lugar en el modo de la sensibilidad, sin que sea dictada por el interés sensible en tener o disfrutar el objeto. El sentimiento de sí mismo tampoco desarrolla un concepto definido de sujeto, pues dicho sentimiento se cumple sólo en la operación pura con motivo de la experiencia de una afectación sensible" (Bubner, 2010, p. 397).

${ }^{7}$ Bubner indica al respecto: “Arte es apariencia en su autonomía y, por lo tanto, el arte es incapaz de calificarla como apariencia. La apariencia que no puede ser reconocida como apariencia se considera engaño y tiene que abandonarse en cuanto se presente la comprensión. El arte, que tiene su ser en la autonomía de la apariencia, no puede, por lo tanto, ser legitimado jamás mediante el concepto lógico de la apariencia referida a la verdad" (2010, p. 400). 
Platón advertía le parece a Bubner sintomático, pues explica los efectos que la apariencia artística posee sobre la verdad. Existiría, según nuestro análisis, en la consideración de Bubner un régimen autárquico de la apariencia estética respecto de la verdad; su paradoja no implica ponerla en relación a algo que encubre o que es anterior a ella, sino a una lógica propia. En consecuencia, los intentos de "los teóricos de la experiencia estética" (Menke, Seel y Wellmer) por encontrar en la relación entre la experiencia estética y las potencialidades del arte una verdad renunciarían a la autonomía del arte subsumiéndola en los planes de la verdad filosófica o autocrítica de la misma. La autonomía que la apariencia estética ofrecería no es aprovechada, a juicio de Bubner, por la estética filosófica en tanto se esfuerza en "reflejar sólo el concepto en el arte en lugar de concebir conceptualmente el arte" (2010, p. 401).

La oposición a los teóricos mencionados, entonces, es frente a la insistencia de éstos en asignarle al arte un valor de verdad como derecho. No sólo que vuelven a un tipo de consideración de la experiencia estética como las estéticas heterónomas, sino que además la experiencia estética generarían un acceso al mundo de forma privilegiada, e incluso, más verdadera que otras formas de conocimiento. No parece ser legítima para Bubner la aplicación de las categorías estéticas en una teoría del conocimiento en la cual la apariencia se vería claramente afectada en su desvalorización. El autor defiende la idea de que el arte no tenga nada para decirle a la filosofía, ya que, en dicha posibilidad radica el beneficio de una estética filosófica. La apariencia estética sería la única estructura capaz de sostener a la experiencia estética que se resiste a la aprehensión conceptual. Nuevamente, Bubner recurre a un modelo de autarquía estética por medio de la apariencia, pero ahora incluye la exposición de la experiencia estética a la apariencia artística. Señala:

Es más bien la inaprehensible autonomía, no sostenida por nada, de los fenómenos estéticos la que invita al pensamiento a dominarlos, dejándolos, sin embargo, completamente desamparado. En el arte aparece algo que puede y quiere ser comprendido, pero que definitivamente no resiste ninguna intervención. (Bubner, 2010, p. 402).

Pese a las críticas realizadas por Rudiger Bubner, estos teóricos de la experiencia estética han contribuido a pensar en la dimensión social del arte. La importancia de estos estudios en el debate alemán sobre la estética ha significado una nueva comprensión de la crítica estética ( $C f r$. Bertram e Bertinetto, 2016). En ese marco, el texto de Bertram, al polemizar con las posibilidades críticas que estos autores intentan potenciar a partir del concepto de experiencia estética, parece constituirse como un aporte a esta 
discusión iniciada por Bubner. Como hemos indicado, el lector no debe perder de vista la oposición al paradigma de la autonomía del cual los teóricos de la experiencia estética serían sus representantes. Pero, a diferencia de las precursoras críticas kantianas de Bubner, Bertram enfrenta este paradigma a partir de la evidencia de la objetividad de la obra y su recepción, a los fines de mostrar cómo la autonomía es una falta de la autonomía en la propia autonomía, algo que es característico de las experiencias estéticas como actividades interpretativas. Según su consideración, "no se trata $[\ldots]$ de actividades de los sujetos receptores. [...] Los sujetos que tienen experiencias son autónomos en sus actividades. Pero si las actividades son guiadas por los objetos, resulta una experiencia de la falta de autonomía en la autonomía" (Bertram, 2016a, p. 141).

Hacia el final del texto y en varios pasajes intermedios se deja evidenciar una posición hermenéutica cercana a la de Gadamer y Heidegger que permite reconocer mejor la posición del texto en relación al arte y los debates contemporáneos. De hecho, podríamos hacernos eco de la observación de Federico Vercellone a la traducción italiana de El arte como praxis humana, según la cual "siamo dunque nel quadro di un fecondo rinnovamento della tradizione ermeneutica" (2017, XVI). Como hemos insistido, el concepto de interpretación empleado por Bertram pone de relieve el cuño hermenéutico de su consideración de la obra de arte, en tanto se vuelve el medio por el cual colocar al arte en la praxis humana, como también la oportunidad de conducirnos en las posibilidades de apertura al futuro. Esto último ha sido remarcado por Bertram, recientemente, en un artículo en homenaje a Gianni Vattimo, donde hace hincapié en considerar a la obra de arte como una "practice that allows us to develop indeterminacy within the human form of life and thus enables us to retain an openness towars the future" (Bertram, 2016b, p. 23).

Finalmente, uno podría preguntarse si la consideración interpretativahermenéutica de Bertram no parece reintroducir la confianza en la categoría de obra de arte, una categoría que no parece convencer a quienes intentan explicar las prácticas contemporáneas del arte. Aceptar que la obra comporta, constitutivamente, la oportunidad interpretativa para abrirnos posibilidades de futuro podría conducir a una conformidad acrítica y no dialéctica de nuestra relación con el arte como, precisamente, praxis humana. 


\section{Referencias bibliográficas}

Bertram, G. (2014). Kunst als menschliche Praxis. Eine Asthetik. Berlin: Suhrkamp Verlag.

Bertram, G. (2016a). El arte como praxis humana. Una estética. España: Comares.

Bertram, G. (2016b). In Defence of a Hermeneutic Ontology of Art. Trópos. Journal of Hermeneutics and Philosophical Criticism, 1(IX), 11-24.

Bertram, G. e Bertinetto, A. (2016). Introduzione. En: G., Bertram e A. Bertinetto (Eds.), Il bello dell'esperienza. La nuova estetica tedesca (pp 209-226). Mailand: Marinotti.

Bubner, R. (2010). Sobre algunas condiciones de la estética actual. En: R. Bubner, Acción, historia y orden institucional. Ensayos de filosofía práctica y una reflexión sobre estética (pp. 357-410). Buenos Aires: FCE.

Menke, Chr. (2008). Kraft. Frankfurt: Suhrkamp.

Menke, Chr. (1988). Die Souveränität der Kunst: Ästhetische Erfahrung nach Adorno und Derrida. Frankfurt a.M.: Athenäum.

Vercellone, F. (2017). Prefazione all'edizione italiana. En: G. Bertram, L'arte come prassi umana. Une estética (pp. 11-20). Milano: Raffaello Cortina Editore. 